\title{
Kernos
}

Revue internationale et pluridisciplinaire de religion grecque antique

7| 1994

Varia

\section{Marcos MARTÍNEZ HERNÁNDEZ, Canarias en la Mitología. Historia Mítica dei Archipiélago}

\section{Monique Mund-Dopchie}

\section{CpenEdition \\ Journals}

\section{Édition électronique}

URL : http://journals.openedition.org/kernos/1140

DOI : 10.4000/kernos. 1140

ISSN : 2034-7871

\section{Éditeur}

Centre international d'étude de la religion grecque antique

Édition imprimée

Date de publication : 1 janvier 1994

ISSN : 0776-3824

\section{Référence électronique}

Monique Mund-Dopchie, « Marcos martínez hernández, Canarias en la Mitología. Historia Mítica dei Archipiélago », Kernos [En ligne], 7| 1994, mis en ligne le 20 avril 2011, consulté le 24 septembre 2020. URL : http://journals.openedition.org/kernos/1140 ; DOI : https://doi.org/10.4000/kernos.1140 
là concentré. Les deux autres types de manifestation de la parole sont les sentences des rois et le chant du poète. Les premières ne sont pas sans défaillance car le roi est le simple garant de formules à mettre en œuvre. Il n'en va pas de même pour l'aède en qui la voix divine ellemême est déposée, dans le cadre d'une initiation que nous révèle le prologue de la Théogonie. Le poète se trouve à la charnière entre la voix divine et les approximations humaines, rempli d'une révélation à transmettre, d'une vérité dont l'essence même se trouve dans les mots qui la disent. Contrairement à ce qu'on a parfois cru, Hésiode ne pose pas la question de la vérité comme telle - imbu de sa mission, il la possède ! - mais bien celle de sa transmission. Dès lors la révélation peut revêtir les atours de la fable à fonction persuasive. L'étude de la fonction de la parole permet de discerner à la fois la mission de poète et les voies qu'il emprunte pour la mener à bien. C'est la structure même des deux grandes cuvres hésiodiques qui s'en trouve éclairée, brillamment.

L'ouvrage de M.-Chr. LeCLerc possède la rigueur, l'information, la clarté d'exposition, la finesse d'analyse qui font les travaux importants, et ce n'est pas lui rendre justice que de le résumer ainsi. L'historien de la religion grecque y découvrira un Hésiode préoccupé d'une humanité dont la mortalité et l'imperfection langagière se définissent au fil de la mise en place de l'univers. Il n'y a pas d'anthropogonie hésiodique, mais on comprend mieux la perception de l'humain et du divin dont il témoigne après avoir lu une telle analyse.

Vinciane Pirenne-Delforge (Université de Liège)

Marcos Martínez Hernández, Canarias en la Mitología. Historia Mítica del Archipiélago, Santa Cruz de Tenerife, Centro de la Cultura Popular Canaria, 1992. 1 vol. $15 \times 21 \mathrm{~cm}, 168$ p., 14 ill. (Historia Popular de Canarias). ISBN : 84-7926-082-3.

Avec un esprit de synthèse remarquable et beaucoup de brio, Marcos Martínez décrit les liens privilégiés que les Canaries ont entretenus avec des mythes antiques et médiévaux. Du fait de leur situation à l'extrémité occidentale de l'œcoumène, telle qu'elle est définie jusqu'à la découverte de l'Amérique, à cause de leur caractère insulaire, propice au développement de légendes, enfin grâce à leur climat agréable et à leur végétation luxuriante, elles apparaissent comme des terres où l'âge d'or n'a jamais cessé d'exister. Il n'est dès lors pas surprenant que des écrivains anciens et modernes aient été tentés d'y installer les Champs Élysées, les îles des Bienheureux, des îles heureuses, le Paradis Terrestre - qu'il s'agisse de l'Éden biblique, des paradis celtiques ou des escales merveilleuses de saint Brandan -, le Jardin des Hespérides 
et l'Atlantide. C'est leur démarche qui est envisagée dans le présent ouvrage.

Avant d'être mise en relation avec l'archipel, chacune de ces légendes est soigneusement retracée à l'aide des sources les plus explicites et les plus chargées de sens, située dans son contexte et dans son évolution, interprétée selon les grilles les mieux établies. Les exposés sont clairs, fondés sur une bibliographie, limitée mais récente, parsemés de tableaux récapitulatifs, qui reflètent de façon fort heureuse les chemins sinueux des traditions légendaires. Il ne faut donc pas s'attendre à des analyses qui renouvellent la connaissance de mythes et de fictions célèbres; ce n'est d'ailleurs pas le but de l'A. En revanche, l'excellent ouvrage de Marcos Martínez met en évidence et explique la place exceptionnelle que l'archipel des Canaries a occupée et occupe encore dans l'imaginaire occidental. À ce titre, il relève non seulement de l'étude des mythes et des Canaries, mais aussi de l'histoire des mentalités.

Monique Mund-Dopchie (Université de Louvain-la-Neuve)

J. Poucet, J.-M. Hannick, Aux sources de l'antiquité gréco-romaine. Guide bibliographique, Louvain-la-Neuve, Artel, $1993^{3} .1$ vol. $16 \times 23$ cm, 291 p. ISBN : 2-87374-019-1.

Voilà un outil de travail qui rendra de multiples services à tous ceux, étudiants, professeurs, ou amateurs éclairés, qu'intéresse la période gréco-romaine. Dans un méritoire souci de décloisonnement, c'est l'ensemble des disciplines à mettre en cuvre pour étudier l'antiquité qui sont ici envisagées. L'ouvrage s'organise en trois parties. La première présente les sources littéraires, épigraphiques, papyrologiques, archéologiques, numismatiques; la deuxième présente les grands ouvrages de consultation (dictionnaires, encyclopédies, manuels, etc.), et la troisième, sans doute la plus difficile à organiser et la plus susceptible de prêter le flanc à la critique, propose une bibliographie d'orientation couvrant à la fois l'histoire des études classiques, la transmission des textes, la littérature, la linguistique, l'histoire générale, la vie sociale, économique, la religion et la mythologie, la pensée morale, sociale, politique, philosophique, les arts, la survie et les héritages de l'antiquité. Des index complètent l'ouvrage et en facilitent la consultation.

Vinciane Pirenne-Delforge (Université de Liège) 